\title{
Building Information Modeling (BIM) and Sustainability - Using Design Technology in Energy Efficient Modeling
}

\author{
Eng. Parisa Esmaeili Moakher ${ }^{1}$ and Prof. Dr. S. S. Pimplikar ${ }^{2}$ \\ ${ }^{I} 3$ rd floor, Mersedeh apartment, East Bahman Avenue, Farhang Street, Sari, Iran \\ ${ }^{2}$ Department of civil Engineering, MIT College, Paud Road, Camp, Pune 411038, Maharashtra, India
}

\begin{abstract}
This study intends to highlight how some of the latest design technology can be used to accurately analyze daylight in our buildings today. Architecture and Engineering firms are using Building Information Modeling (BIM) software to model their design projects three-dimensionally these days. Some of the popular modeling software platforms for Architecture are, Autodesk's Revit Architecture, Autodesk Ecotect Analysis and Green Building Studio.

Using BIM allows the user to export the model into analysis tools for daylight and energy analysis. Revit Architecture is used for BIM models, allowing the user to export to daylight analysis tools like Ecotect and $3 d$ Studio Max Design. As the use of BIM in projects becomes more popular, the opportunities to seamlessly integrate daylight analysis into the design process become more abundant and more convenient.

It is found that using this technology, both the owner and designer can be more confident of what the outcome will be before the building is even constructed. This has the potential to save money from design changes and energy costs as well as material changes and retrofitting that is common from older methods of daylight control. In the end it can improve the aesthetics of the building, improve visual comfort and reduce the overall electrical lighting usage within the building.
\end{abstract}

Keywords: Sustainability, Building Information Modeling (BIM), Architectural designs, and Importance of Energy Efficiency

\section{Introduction}

\section{Review of Current State of Profession}

Over last 20 years information technology has revolutionized the design and production of movies, music, airplanes and, machinery. Architects and engineers are now applying similar tools to building design. The most sophisticated of these tools are delivering continuous and immediate feedback on far greater range of characteristics than conventional design tools. Materials quantity and properties, energy performance, lighting quality, site disturbance and what-if comparisons between new construction and renovation are some types of information that are easily available from these tools. This approach to building design is so different from using conventional CAD software that the industry has a new name for it: Building Information Modeling (BIM). [1] $\mathrm{BIM}$ is an integrated process which is used to facilitate the exchange of design and construction information to project participants. BIM models can be extended to store energy performance data such as power consumption, temperature, $\mathrm{CO} 2$ emissions, occupancy and humidity. Furthermore, the adoption of the sustainable guidelines such as LEED ${ }^{\mathrm{TM}}$ by federal, state and local governments calls for more comprehensive BIM models describing environmental performance such as indoor air quality, water consumption, and solid and hazardous waste (USGBC 2009).

BIM has risen to prominence out of a desire to streamline the building design and documentation process, to simplify construction management, and to provide the owner with inherently better capabilities for ongoing facilities management during building occupancy. The initial benefits of BIM were seen through the lens of economics: by making building design, construction, and maintenance more efficient, we can ultimately deliver a better project value at a lower construction cost. On the other hand, "Sustainable Design" has become another buzz word in the construction industry. It has emerged out of global concern for the state of our natural environment. As we add more buildings to our collective built landscapes, sustainable thinking is needed to meet the future challenges of land use, energy consumption, and availability of material resources for building construction. Although BIM and Sustainable Design have emerged from somewhat different underlying market factors, they share a significant common thread: the success of both endeavors depends heavily on a front loaded, deeply integrated building design philosophy that aims to include all team players from the very beginning of a project.

Applying BIM for sustainability can be a great advantage. For energy analysis the model can be imported into programs such as IESVE and eQUEST to determine the efficiency of the building. For daylight design and analysis you the model can be brought into Ecotect Analysis, 3ds Max Design and Daysim. The choice of software depends on the type of analysis desired. 3ds Max Design and Daysim has been validated in 
other studies. [2] This paper will provide an overview of how purpose-built BIM solutions and integrated analysis tools can help to assess building performance, prioritize investments, and evaluate proposals to reduce operational costs, conserve energy, reduce water consumption, and improve building air quality, helping to meet sustainability and energy-efficiency goals.

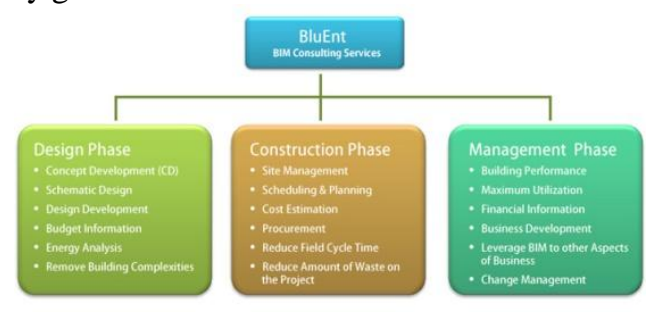

\section{Need For Study}

In spite of the recent efforts toward sustainability, lifecycle energy efficiency and the resulting value and corresponding cost savings are not key criteria in the building development process, resulting in lost opportunities to maximize the use of energy efficient building design and technology options. Energy and performance analysis are typically performed after the architectural design and construction documents have been produced, if at all. This lack of integration into the design process leads to an inefficient process of retroactively modifying the design to achieve a set of performance criteria.

Most importantly, some issues are involved in the application of design analysis integration in actual building design practice as follows: (1) the difficulty of effective exchange of information among the stakeholders (2) the amount of design information/knowledge (3) the significant amount of time and effort required for finding the optimal design alternatives, and (4) the different assessment method required at each building design stage. Building energy consumption is affected by architectural elements (geometry, type of envelope, floor plan and site plan) which are determined from the design stages.

The use of BIM-based energy performance assessment during the design stages is believed to be essential to achieve energy-conscious green buildings. BIM allows architects and engineers to receive building information as a detailed and digitalized virtual model. However, the use of BIM-based energy performance simulation in the design phase of a building project is still controversial. In other words, for an improved BIMbased simulation, one of the important issues is how architects and HVAC engineers cope with interoperability between design and energy performance tools.

Therefore the paper intends to introduce various analytical BIM-based simulations which can be used during early design phase of sustainable construction for selection of optimal design alternatives on multicriteria problems. It can be used as a basis to assist designers and engineers to obtain subtle knowledge about application of information technology in sustainable construction and pave the way for further improvement.

\section{Literature Review}

Following points emerged from the literatures review:

1. $95 \%$ of firms using Green BIM will do energy performance simulations within two years, compared with $73 \%$ now. $79 \%$ of non-green BIM firms will conduct such simulations, a dramatic increase from only $21 \%$ currently. This rapid increase reflects the growing importance of energy efficiency in buildings and the capacity BIM tools have for this purpose. [3]

2. BIM allows architects and engineers to become "digital" master builders who are able to see the building, its materials, its structures and its performance in real time as it being designed, and (more importantly) before the design is converted to very expensive bricks and mortar or more likely metal studs and gypsum board. At the same time, this model can very efficiently provide a fully coordinated set of conventional documents that is accurate and reliable. [1]

3. BIM and sustainable design are connected by utilizing the capabilities of the model to provide useful data to analyse tools that report on a design's predicted performance on key sustainable characteristics. For example, BIM authoring tools can convert the model into a non-proprietary format for sustainable design information, such as Green Building xml, or gbxml. [4]

4. Building Information Modeling (BIM) allows for multidisciplinary information to be superimposed within one model incorporating structural, mechanical, electrical, plumbing and lighting (Tucker, 2010). Hence an ideal opportunity exists for sustainability measures and performance analysis to be integrated within the BIM model (Azhar \& Brown, 2009). With programs such as Autodesk Ecotect that can import BIM models, interior designers can holistically study the performance of interior environments leading to creation of more comfortable, healthy, and sustainable spaces for its inhabitants. [5] 


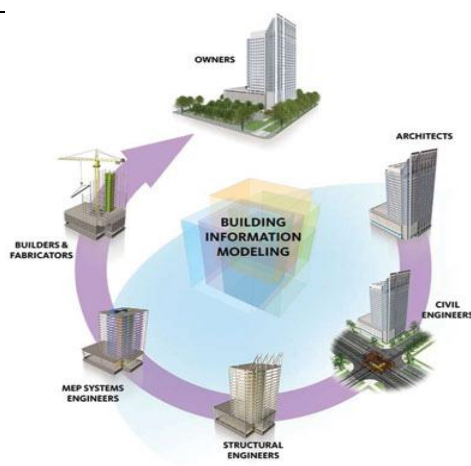

6. Autodesk Building Information modeling (BIM) solutions help make sustainable design practices easier, more efficient and less costly. BIM solutions from Autodesk-Autodesk Revit Architecture software and Autodesk Revit MEP Software- are interoperable with Autodesk Ecotect Analysis software.

7. IFC is a common language which may be used by all engineering disciplines, and which enables sharing information between all AEC/FM (Architecture, Engineering and Construction / Facility Management) project participants and storing the entire valuable data in one virtual model unit that can be preserved and used beyond the life of the project (BuildingSMART 2011c).

8. It is often difficult to leverage the full potential of BIM due to inadequate data exchange between BIM and energy simulation programs. Although the potential of using BIM for energy simulation is well known, a systematic approach to share the necessary information is yet lacking (Young, Jones and Bernstein 2009). Data exchange between BIM and simulation programs is currently limited to the transfer of 3D geometries of the building projects. Building systems data related with HVAC and internal loads such as occupancy and lighting should be included in data exchange between BIM and energy simulation programs to avoid any repetitive data inputs. [6]

\section{Objectives And Data Collection Techniques}

In spite of the recent efforts toward sustainability, lifecycle energy efficiency and the resulting value and corresponding cost savings are not key criteria in the building development process, resulting in lost opportunities to maximize the use of energy efficient building design and technology options. Energy and performance analysis are typically performed after the architectural design and construction documents have been produced, if at all. This lack of integration into the design process leads to an inefficient process of retroactively modifying the design to achieve a set of performance criteria. In addition, traditional CAD-based planning environments do not support the possibility of early planning and decision making process. [7] Although BIM is a recent development, a lot of research has been conducted in order to further enhance its capabilities in design and construction.

However, there has been very little research done so far on the impact that BIM has on sustainable construction practices. Hence, the overall goal of present paper is to introduce various BIM - integrated software to increase sustainable building performance. It is anticipated that the conclusions and recommendations may guide the procurement of future sustainable educational facilities.

A thorough literature review is conducted in this area with the majority of information from international sources. The main strategy adopted is:

- Collection of data with search in existing observations and studies

- Collection of data through documentation and archival evidence

\section{BIM and Sustainable Construction}

Building Information Modeling (BIM) is both the creation of a set of digital models of a planned or built environment, as well as the process of working collaboratively with these models during the lifecycle of that facility. BIM typically contains a set of 3D models and information about relevant components and attributes. Currently, BIM is used mostly during the design phase of a building project although its use during the construction and operation phases is increasing.

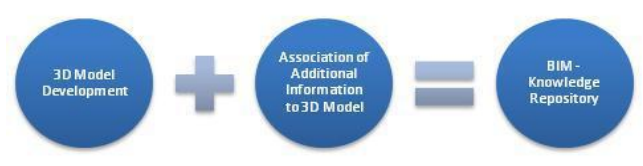


Sustainability means meeting the needs of today without compromising the ability of future generations to meet their needs. Most of the advances promoted by the sustainability mega-trend are derived from something very intangible, software. Software is a sustainable product, especially when it comes to supporting other sustainable tools to do more with less.

The sustainability of the construction business can be measured by defining how 'green' the building is in terms of energy and material consumption during its construction, usage, maintenance, and demolition. There is no need to invent that much new; a lot can be learned from established practices used in, for example, electricity distribution and the maintenance processes of off-shore structures. Software can be used to optimize material selection, utilize the resources of the construction process more efficiently, and improve the maintenance of buildings by a diversity of applications.

In current practice, many digital models do not contain sufficient information for building performance analysis and evaluation- the building blocks of sustainable building design. As with traditional physical models and drawings, evaluating building performance based on graphic representation of conventional CAD or object$\mathrm{CAD}$ solutions requires a great deal of human intervention and interpretation, which renders the analysis too costly and/ or time consuming. The BIM-based building modeler represents the building as an integrated database of coordinated database. Beyond graphically depicting the design, much of the data needed for supporting sustainable design is captured naturally as design of the project proceeds. Linking the building model directly to the analysis software, allows for preliminary verification of the "broad stroke" or "big picture" sustainable design goals. With architectural computer software design tools and modeling programs, the design team can quickly generate multiple design options during the schematic phase that take into account site specific characteristics such as solar orientation and sky path.

\section{Energy Analysis}

Quality sustainable design requires an understanding of how a building will perform after it's built, which in turn requires computer-based simulation software for rigorous building analysis. The advent of BIM (building information modeling) offers even greater opportunities for building analysis by pairing the analysis software and BIM for the seamless assessment of building performance. For decades, energy simulation software tools have been available to assist in designing energy-efficient buildings. However, most building energy analysis is conducted late in design, when other building features cannot be changed. Using traditional CAD solutions, energy analysis can be a painful process. If it's a 2D solution, either special 3D analysis models are created or manual plan take-offs from the floor plans are done. If it's a 3D solution, building data is extracted from disparate CAD files and then merged into a single input file. In most cases, the data must be massaged for analysis import and then the output has to be "translated" for the designer's consumption.

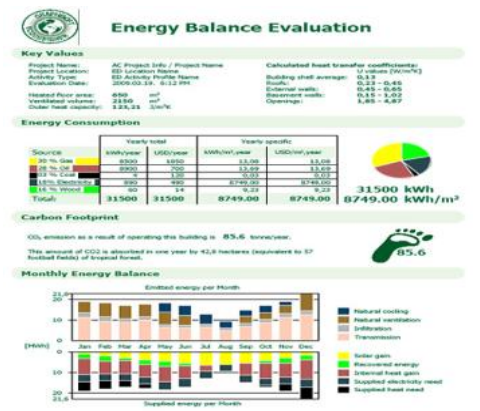

Now, with Revit Architecture and Green Building Studio, the process is simple. When you initially register for Green Building Studio web service, you download a small Green Building Studio client. Then each time you run an analysis, you simply make sure the rooms have a room number (the unique space ID used in the analysis programs) and the model has a defined project type and address (for building codes, local climate information, etc.). On the file menu, you click Export, select the file type and save the export file to your hard drive. Then launch Green Building Studio from your Internet browser and submit your saved file for energy analysis. Within minutes you can view the results, which provide energy statistics for your project and recommendations to improve your design based on local standards for building type, climate, etc. You can then modify your building design and repeat the process to see what impact a design change has on the energy efficiency of the building. This simple process belies enormous computational power. Behind the scenes, Green Building Studio relies on a large network of relational databases containing hourly weather data, design data, and regionally relevant libraries of default building characteristics with common energy code baselines. It will even make recommendations regarding building products appropriate to any building (greatly simplifying the early specification process). 


\section{Daylight Analysis}

Daylighting, the practice of using natural light to illuminate buildings, not only makes people more comfortable and productive, it can sharply reduce the electrical lighting load and subsequent heat and energy loads. A sustainable high performance design can derive much of its ultimate success from effective relationship to, and integration of sun's energy in to the design of the building envelope and fenestration. Using your building model for sustainability can be a great advantage. For daylight design and analysis the model can be brought into Ecotect Analysis, 3ds Max Design and Daysim. Older processes would include creating a separate digital model for analysis or creating a physical model and placing it on-site to measure the daylight levels. This could take a great deal of time to get an accurate analysis. Now the BIM model can be exported to a format that can be imported into Ecotect Analysis or 3ds Max Design. This saves time and can be more accurate since the materials are assigned in the model, windows are placed in precise locations, and curtain walls and storefronts are modeled to exact dimensions.

When bringing this information into 3ds Max Design, the program will recognize most material assignments and all of the model geometry. Furthermore, in the 3ds Max Design program it is possible to modify and adjust material characteristics, glazing characteristics, reflectance and refractive values and many other variables. This takes into account the entire interior environment of the building so that the designer can adjust these elements as necessary for the visual comfort of the future occupants. It is very important to get more accurate feedback from the daylight analysis, especially because each material has specific reflective and refractive values to consider.

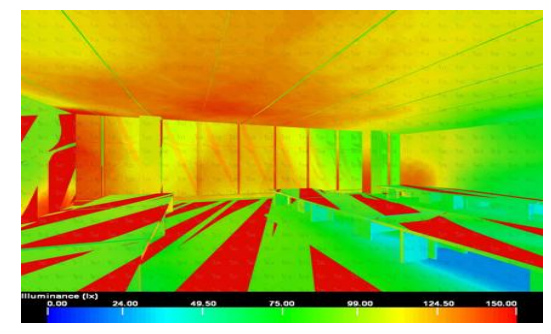

One way of taking a BIM model (Revit Architecture) into daylight analysis software (3ds Max) is First, model the building in Revit to the extent that it would be ready for analysis (preferably it has interior spaces defined and windows positioned). By using Day light system and accurate whether data file and most importantly by setting up the cameras, the first set of analysis can be run. Rapid energy modelling is a streamlined process that helps you analyze and estimate building energy consumption using Building Information Modeling (BIM) solutions. With a smaller budget, shorter timeframe, and less initial data, building professionals can evaluate expected building performance and identify areas for improvement.

This paper outlines rapid energy modeling workflows using Autodesk solutions and documents results from real-world validation. The table below shows how the various software options are used in the three-step rapid energy modeling process.

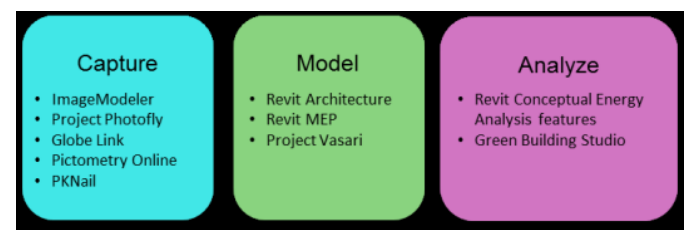

The combination of these various software options translate into a series of distinct rapid energy modeling workflows.[8]

\section{Autodesk Revit Architecture}

A computable Revit design model is a great fit for the analyses needed for sustainable design - even during schematic design. As soon as the layout of a building's walls, windows, roofs, floors, and interior partitions (elements that define a building's thermal zones) are established, a Revit model is ready for whole building analyses.

Performing these analyses in a CAD workflow is a fairly difficult undertaking as the CAD model has to be exported and carefully massaged to work with analysis programs. In addition, most analysis software is complex and requires special training - making it unsuitable for casual users like architects or designers. Furthermore, the output of most analysis programs is complicated, making it hard for architects or designers to understand what to do to improve upon their designs. [9]

Revit Architecture 2010 is used to develop the 3D model. Built for Building Information Modeling (BIM), Autodesk ${ }^{\circledR}$ Revit ${ }^{\circledR}$ Architecture software helps to capture and analyze most innovative design concepts 
and maintain vision through documentation. The information-rich models that the software provides support decision-making for sustainable design, clash detection, construction planning and fabrication, while helping to work collaboratively with engineers, contractors and owners.

Autodesk Revit Architecture generates every schedule, drawing sheet, 2D view, and 3D view from a single foundational database, automatically coordinating changes as the project develops and evolves.

Bidirectional Associativity: A change anywhere is a change everywhere. In Autodesk Revit Architecture, all model information is stored in a single, coordinated database. Revisions and alterations to information are automatically updated throughout the model, minimizing errors and omissions

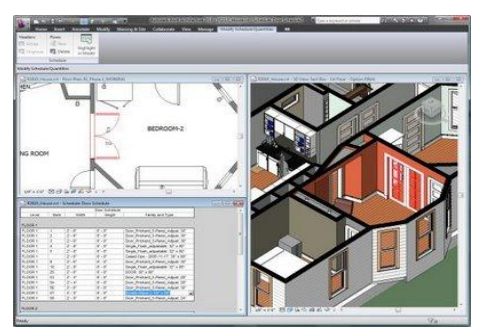

Schedules: Schedules provide another view of the comprehensive Autodesk Revit Architecture model. Changes to a schedule view are automatically reflected in all other views. Functionality includes associative splitschedule sections and selectable design elements via schedule views, formulas, and filtering.

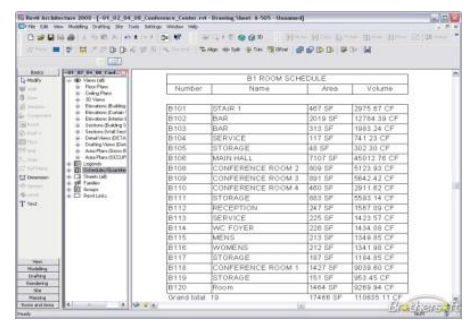

Parametric Components: Parametric components, also known as families, are the basis for all building components designed in Autodesk Revit Architecture. These components offer an open, graphical system for design thinking and form making, while providing the opportunity to adjust and express design intent at increasingly detailed levels. Use parametric components for elaborate assemblies, such as cabinetry and equipment, as well as for elementary building parts, such as walls and columns. Best of all, no programming language or coding is required.

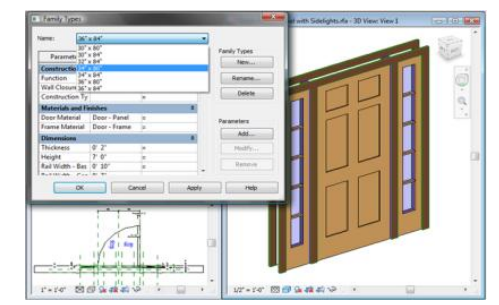

Material Takeoff : Calculate detailed material quantities with Material Takeoff. Ideal for better calculation of material quantities on sustainable design projects and cost estimates, Material Takeoff helps smooth the material quantity tracking process. As projects evolve, the Autodesk Revit Architecture parametric change engine updates material takeoffs.

Sustainable Design: Conceptual energy analysis tools help one to make every design more sustainable. Cloudbased analysis tools are used to quickly compare the energy consumption and lifecycle costs of design alternatives right from within Autodesk Revit Architecture software. Analysis results are presented in a highlyvisual, graphical format for easy interpretation.[10]

Building Information Modeling (BIM) is poised to be a major innovation in architecture industry in the 21 st century, and Revit supplies oxygen to this wonderful innovation. There are considerable numbers of reasons behind the increasing acceptance of Revit software in architecture industry. BluEnt, a globally leading construction documentation firm, has observed the following advantages of Revit Building Information Modeling software: 
1. Preview the Future Home in 3D BIM Modeling: Revit Parametric modeling is a significant tool for conceptual design. With Revit software, architectural designers can quickly sketch a rough layout of the floor plan, or make changes to the standard set of building designs and instantly let their customers preview their future homes. 3D design views give designers to try out different design ideas and guide their design decisions at early stage.

2. Quick Changes to Design, No Repetitive Tasks: During the design phase, the building structure and floor plans needed to be modified frequently. With Revit BIM software, architecture designing and drafting becomes very fast and accurate. In Revit architecture model, all building components such as plans, sections, and elevations are intelligently connected to each another. Whenever a change is made to the model, the software automatically updates every related component, affecting the whole building model.

3. Vast Library of Parametric Building Components: BIM authoring tool Revit software comes with a full set of parametric building design components. It also allows quick changes to the existing components. It stores the newly created or customized parametric objects to be reused in other projects. While designing a new project, architectural designer can use the stored parametric building objects for quick references to the prospective clients.

4. High Quality Construction Documents: 3D modeling capacity of Revit architecture enables designers and drafters to easily identify the clashes and areas of congestion, and resolve them early in the process. It results in error-free and high quality construction documentations.

5. Accurate Estimation of Quantities and Cost: One of the most important advantages of building information modeling software is the automatic generation of bill of quantities (BOQ). BIM modeling software like Revit produces accurate material quantity takeouts as a by-product, with less-efforts. This advantage helps the contractors and owners to determine if the project adheres to budgets.

6. Improved Coordination: BIM drafting software Revit unifies design, drafting, construction and facility management processes in single environment, allowing all stakeholders to remain updated and aware of their responsibilities, and thus improving overall coordination. A total understanding by everyone on the project of what's happening removes the design conflict and risks.

7. High Level of Flexibility: Unlike AutoCAD, Revit allows all project data to be stored in single project file. It allows multiple users to work on the same project file and merge their changes with every save. Besides, Revit exports and imports DWG, DXF, DGN, PDF, JPEG files.

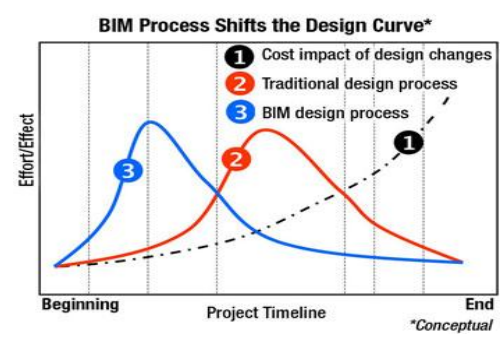

The list of Revit advantages continues. It is proved that BIM approach is "significantly more efficient" than the traditional drafting-based approach. Architectural design and drafting firms are realizing the benefits of BIM implementation software. For example BluEnt BIM, a leading BIM construction documents developer has started drafting in Revit BIM software for large and complex building practices, and delivering the clients significant benefits in terms of TIME and COST.

\section{Autodesk Ecotect Analysis}

Autodesk ${ }^{\circledR}$ Ecotect ${ }^{\circledR}$ Analysis 2011 software is a comprehensive concept-to-detail sustainable design analysis tool, providing a wide range of simulation and analysis functionality on a single platform. Revit-based design models can be exported to gbXML format and imported directly into

Autodesk Ecotect Analysis for simulation and analysis throughout the design process. At the onset of the design process, very early stage Autodesk Revit Architecture massing models can be used in combination with site analysis functionality in Autodesk Ecotect Analysis to help determine the optimal location, shape, and orientation of a building design - based on fundamental environmental factors such as daylight, overshadowing, solar access, and visual impact. What makes Ecotect a very popular tool in its category is its extremely userfriendly interface. Since its introduction into the market, it has represented a big step forward in terms of "usability" if compared with other building simulation tools. The new Ecotect Analysis includes an expanded array of environmental analysis and simulation capabilities including shadows and reflections, shading design, solar analysis, photovoltaic array sizing and load matching, lighting design, right-to-light analysis for neighboring buildings, acoustic analysis, thermal analysis, and ventilation and airflow. An example of solar 
analysis in Ecotect is shown in Figure (a), where a freeform façade is being analyzed for solar radiation exposure so to determine the optimal shape for minimizing direct solar gains. Another example is shown in Figure (b), where the daylight factors and illuminance levels are calculated and used to design a space to maximize the use of daylighting. Other examples include shading design analysis, shown in Figure (c) and ventilation and airflow analysis, shown in Figure (d).

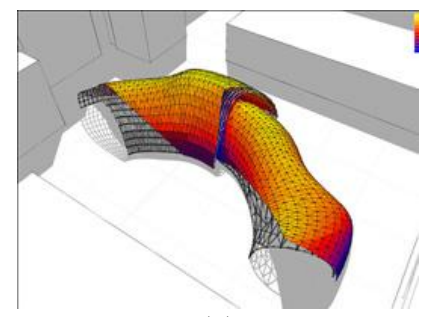

(a)

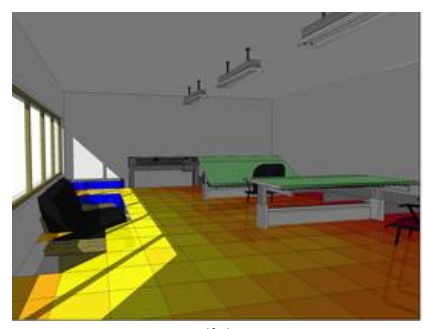

(b)

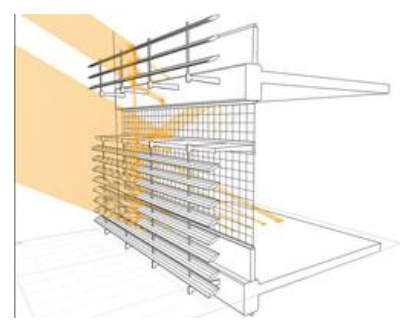

(c)

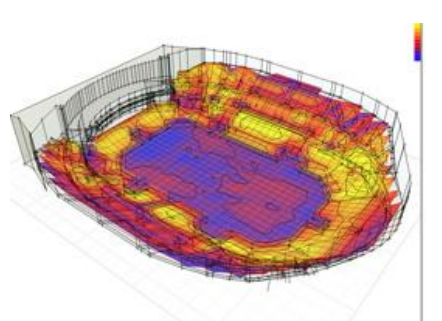

(d)

Once the fundamental design parameters have been established, Autodesk Ecotect Analysis can be used again to rearrange rooms and zones, to size and shape individual apertures, to design custom shading devices, or to choose specific materials - based on environmental factors such as daylight availability, glare protection, outside views, and acoustic comfort.

\section{X. $\quad$ Features of Autodesk ${ }^{\circledR}$ Ecotect ${ }^{\mathrm{TM}}$ Analysis software}

- Visual Feedback: Perhaps the most unique aspect of the software is its visual and interactive display of the analysis results. The inability of the designer to easily interpret the results of analyses is often the biggest failing of building performance analysis software. Autodesk Ecotect Analysis provides actionable feedback to the designer in the form of text-based reports as well as visual displays. These visual displays are more than just charts and graphs. The results are presented directly within the context of the model display: shadow animations resulting from shadow casting analysis; surface-mapped information such as incident solar radiation; and spatial volumetric renderings such as daylight or thermal comfort distribution in a room. This type of visual feedback lets designers more easily understand and interact with analysis data, often in real time. For instance, a designer can rotate a view of surface mapped solar radiation looking for variations 
over each facade, or watch an animated sequence of solar rays to see how sunlight interacts with a specially designed light shelf at different times of the year.

- Usability: Usability in Ecotect Analysis is one of most important features and is due to the good quality of the graphical interface provided, and also to the numerous "presets" and wizard windows that guide the new user to a better management of settings and options. Even though the software is capable of performing multiple environmental analyses its complexity does not compromise its usability. New users find Ecotect a tool to explore and learn while expert users may find it practical, fast and remarkable in some cases (shadow analysis, environmental analysis and pre assessment of solar radiation ). [11]

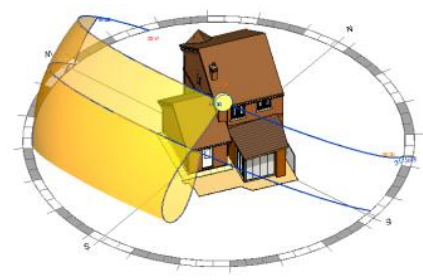

During conceptual design, Autodesk Ecotect Analysis and the Autodesk Revit Architecture model can be used for a variety of early analysis. For example, the designer can perform overshadowing, solar access, and wind-flow analyses to iterate on a form, and orientation that maximizes building performance without impinging on the rights-to-light of neighboring structures. As the design progresses and the elements that define a building's thermal zones are established (the layout of the walls, windows, roofs, floors, and interior partitions), the Revit model can be used for room-based calculations such as average daylight factors, reverberation times, and portions of the floor area with direct views outside.

Ecotect continues to rely on the gbXML format to get model data from BIM applications such as Revit Architecture, ArchiCAD, and Bentley Architecture, and is thus not that closely tied to Autodesk solutions yet. Over time, however, it is possible that Autodesk will build API-level integration between Ecotect and Revit, allowing Ecotect to not only provide "one-click evaluation" for Revit users - similar to what the new Graphisoft EcoDesigner provides for ArchiCAD users - but go beyond it to provide bi-directional integration-where a change made to the model in Ecotect can be brought back automatically into Revit. This level of seamless integration is really what we need for sustainable design analysis to become a fundamental component of the design process.

\section{Autodesk Green Building Studio}

Autodesk Green Building Studio is a web-based service that includes industry leading building energy and carbon analysis tools. Green Building Studio tools enable architects and designers to evaluate the energy profiles and carbon footprints of various building designs. Files are shared between engineering software programs and among engineers and architects early in the design cycle, making sustainable design more efficient and cost effective. It is offered free to members of the Education Community. This web service supports products in the architecture and building design family such as; Autodesk Ecotect Analysis, Autodesk Revit Architecture, Autodesk Revit MEP, AutoCAD Architecture, AutoCAD MEP. Autodesk Green Building Studio supports the needs of those who challenge themselves with design of sustainable and environmentally responsible structures.

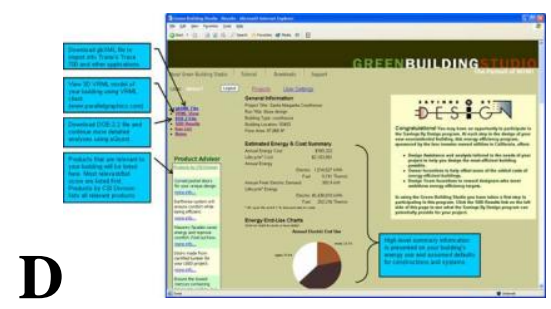

Based on the building's size, type, and location (which drives electricity and water usage costs), the web-based service determines the appropriate material, construction, system and equipment defaults by using regional building standards and codes to make intelligent assumptions. Using simple drop-down menus, architects can quickly change any of these settings to define specific aspects of their design; a different building orientation, a lower U-value window glazing, or a 4-pipe fan coil HVAC system for example. 
The Green Building Studio web-based service analysis process collects data from three sources:

1. Revit ${ }^{\circledR}$ software model. All the building geometry come from the model, including the number of rooms, the connections between rooms, and their relationship to the exterior, exposure, and aspect to the sun; and the shape and total area of built surfaces or openings. If Revit MEP is being used, it can also specify space types, interior loads, constructions, and HVAC equipment.

2. Responses to a few basic questions. In order to explain the building's use or context, a building type is specified and geographical location of the project is entered. It can be used to select a weather station for the project too.

3. Regionalized databases. Based on the above information, Green Building Studio extracts additional information about local weather conditions, construction, and materials. The service automatically adds any information that has not been provided in order to adapt to the requirements as the design evolves.

Green Building Studio relies on an extensive and continually updated database of building constructions, schedules and equipment to supply the assumptions needed to perform whole building energy analysis. You can view these assumptions in the Building Assumptions and Details section of the Energy and Carbon Results for a given simulation. You can modify the assumptions in the Design Alternatives or Project Defaults page.

\section{Features of Autodesk ${ }^{\circledR}$ Green Building Studio®:}

With the Autodesk ${ }^{\circledR}$ Green Building Studio $®$ web-based energy analysis service, architects and designers can perform whole building analysis, optimize energy efficiency, and work toward carbon neutrality earlier in the design process.

- Energy and Carbon Results: The Green Building Studio energy engineering results pages provide extensive information on a building's energy performance and resource use to help compare the relative energy costs of building design scenarios at the conceptual design stage.

- Whole Building Energy Analysis: With Green Building Studio, a virtual building's total energy use and carbon footprint are determined, and can be reduced. Annual energy use, including all electrical and fuel uses, is broken down into lighting, HVAC, and other equipment, with hourly analysis simulations using the DOE-2.2 simulation engine. Further breakdowns of energy use for major electric and gas end users-such as lighting, HVAC, and space heating - are provided in graphical format. Percentages associated with each category can be seen by clicking on the pie charts with your mouse.

- Carbon Emission Reporting: Carbon dioxide (CO2) emissions are reported for nearly all aspects of the building, including on-site fuel use and emissions at power plants that supply electricity to the building. The power plants that generate electricity to the electric grid that serves the building are also summarized by their fuel type.

- Water Usage and Costs Evaluation: A summary is given of the estimated water use, in, and outside the building, based on the number of people in the building, as well as the building type. To obtain Water Efficiency LEED credits, you can make adjustments to your fixtures, and get immediate results in water use calculations. The water usage analysis allows the user to apply a variety of water savings measures, including efficient fixtures, water catchments, and native vegetation. It also provides the potential LEED credits available for these measures.

- Photovoltaic Potential: Every exterior surface on your building is analyzed to determine the amount of electricity that could be generated if photovoltaic panels were on the surface. A high-level summary of your building's photovoltaic electricity potential is provided.

- Energy STAR Scoring: The United States Environmental Protection Agency's ENERGY STAR ${ }^{\circledR}$ score is provided for each building design. The ENERGY STAR score is the basis for the Architecture 2030 goals for carbon and fossil fuel reduction.

- Daylighting: Qualification for LEED daylighting credit is automatically provided for every analysis. Each room's glaze factor calculations are summarized to allow you to determine the action required to improve this factor, and increase eligibility for LEED daylight credits. 
A Revit model can be taken and exported as a gbXML file (Green Building extensible Markup file) and imported into either Green Building Studio, or Ecotect, and through either one, exported out as to an inp (eQUEST ready file format) or idf (EnergyPlus ready file format) - converting that metadata into a file format that will propagate a DOE-2 model instantaneously. [12]

\begin{tabular}{|c|c|c|}
\hline $\begin{array}{l}\text { Comparison } \\
\text { between Green } \\
\text { building Studio } \\
\text { and Ecotect } \\
\text { Analysis }\end{array}$ & $\begin{array}{c}\text { Autodesk } \\
\text { Green } \\
\text { Building } \\
\text { Studio } \\
\text { Measures how } \\
\text { the building } \\
\text { consumes } \\
\text { resources }\end{array}$ & $\begin{array}{c}\text { Autodesk } \\
\text { Ecotect } \\
\text { Measures how } \\
\text { the } \\
\text { environment } \\
\text { impacts } \\
\text { building } \\
\text { performance }\end{array}$ \\
\hline Life cycle costs & $*$ & \\
\hline CO2 Emissions & $*$ & \\
\hline $\begin{array}{l}\text { LEED Credit } \\
\text { Analysis (Lighting) }\end{array}$ & $*$ & \\
\hline Water use & $*$ & \\
\hline $\begin{array}{l}\text { Energy use and } \\
\text { cost }\end{array}$ & $*$ & \\
\hline Airflow/Ventilation & $*$ & $*$ \\
\hline Thermal Loads & $*$ & $*$ \\
\hline $\begin{array}{l}\text { (Day) } \\
\text { Lighting(LEED \& } \\
\text { Energy Savings) } \\
\text { Luminosity Fluxes }\end{array}$ & $*$ & $*$ \\
\hline Shading & & * \\
\hline Solar & & $*$ \\
\hline Acoustic & & $*$ \\
\hline Climate & * & * \\
\hline $\begin{array}{l}\text { Energy code } \\
\text { compliance }\end{array}$ & & * \\
\hline
\end{tabular}

\section{Interoperability}

BIM interoperability specifications and formats remain in their early infancy and often fail to live up to the promise of smoothing interoperability and communication challenges faced by today's construction professionals. Significant long-term challenges remain in addressing the different levels of detail required to support different construction activities including design, analysis, detailing, fabrication and coordination activities. Furthermore, industry groups continue to strive to establish testing and certification of implementations of interoperability standards to ensure that rapid continued progress is made by software developers toward making data transfer reliable and routine. However, current specifications and implementations already provide useful functionality to end users and they actively remain under development and gaining momentum due to efforts by multiple International and North American stakeholder groups including:

- the General Services Administration (the biggest property owner in the US)

- non-profit organizations, such as the National Institute of Building Sciences, building SMART International, the Steel Construction Institute and Green Building XML, and indirectly, by the Construction Specifications Institute

- professional organizations such as the American Institute of Architects, the Associated General Contractors of America and discipline-specific professional societies like the ASHRAE

- Software companies, such as Autodesk ${ }^{\circledR}$, Bentley, Graphisoft.

The efforts to create the new BIM interoperability standards are benefitting from previous technology. IFC standards rely significantly on the EXPRESS language and the work done to standardize CAD geometry exchange (the ISO 10303 - STEP Standard) gbXML and other standards are benefitting from the existing broad technology support for XML schemas for defining domain specific documents. The construction sector provides 
a significant challenge in the scope of the knowledge that needs to be unambiguously defined, represented and agreed upon, even if broken down by discipline or business transaction or construction process.

Other issues remain that have yet to be addressed satisfactorily by the communities developing the standards. These include Intellectual Property (IP), security, risk of misuse and implied warrantee, tracking and authorizing changes, comparison mechanisms and revision management, proprietary documents and linking related documents or data to individual elements of a model. These challenges are not unique to the construction industry but exist wherever knowledge is digitally encoded for exchange between entities and as such, legal approaches, insurance, business practices and technology will all play a part in addressing these issues in the future.

\section{CONCLUSION}

The increase in the number of analysis tools is a testament to the increasing importance of sustainable design in architecture and the need to optimize building performance. The BIM-based design and documentation system is ideally suited for delivering the kind of information that can be used to improve design and building performance. Much of the data needed for supporting green design is captured naturally during the design process and is extracted from the building information model as needed. Revit Architecture facilitates the very complex process of sustainable design like daylighting and solar access, and automates the drudgery of activities like material takeoffs- all the while capturing and coordinating information in the documentation set.

The analysis products it leverages such as Green Building Studio and Ecotect analysis expand its natural capabilities to provide specialized function bounce light calculations, energy analysis and specification management. Linking these products to Revit Architecture make this technology far more accessible than before, giving architects easy access to tools that provide quick feedback on green design alternatives.

In the next step, BIM-integrated software are used to design various components of an Energy Efficient Building to be based on building location and orientation to maximize the efficiency.

[1] Autodesk Revit white paper

\section{REFRENCES}

[2] SOLAR 2010: BUILDING INFORMATION MODELING (BIM) \& SUSTAINABILITY - Using Design Technolgy for Daylight Modeling. (Prepared by: Ben Ridderbos, LEED AP, Vikram Sami, LEED AP, Lord, Aeck \& Sargent Architecture 1201 Peachtree Street NE Suite 300, Atlanta, GA 30361 bridderbos@ lasarchitect.com)

[3] Smart Market Report, (prepared by: Harvey M. Bernstein F. ASCE, LEED AP, Stephen A. Jones, Michele A Russo, LEED AP)

[4] BIM for LEED, By Erin Rae Hoffer, AIA, LEED AP

[5] Poh Lam \& Yeang, 2009; Azhar \& Brown, 2009.

[6] ANALYSIS OF THE DIFFERENCES IN ENERGY SIMULATION RESULTS BETWEEN BUILDING INFORMATION MODELING (BIM)-BASED SIMULATION METHOD AND THE DETAILED SIMULATION METHOD, by: Seongchan Kim \& Jeon-Han W00

[7] Building Information Modeling and sustainability, prepared by: John Doyle)

[8] Streamlining Energy Analysis of Existing Buildings with Rapid Energy Modeling, (prepared by: Autodesk)

[9] BIM and Green Building Studio (1-2-3 Revit Tutorial) prepared by: Rick Rundell, AIA)

[10] Autodesk®Revit@Architecture, Design without compromise. (prepared by: Autodesk)

[11] Using Autodesk Ecotect Analysis and Building Information Modeling, Autodesk® Ecotect ${ }^{\circledR}$ Analysis 2010 , Revit ${ }^{\circledR}$ Architecture 2010 software)\& (Using ECOTECT for Exterior Qualitative Solar Analysis, by: Diego Ibarra, Harvard Graduate School of Design)

[12]- Autodesk Ecitect Analysis, Visualize Sustainable Design, (prepared by: Autodesk)

\section{Authors Bio data:}

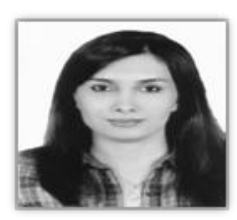

Parisa Esmaeili Moakher obtained bachelor of Engg in Architectural Design and Engineering from Hamedan Azad University, Hamedan, Iran in 2007. She has experienced in a consultant company with four field of engineering (Architectural, Civil, Mechanical and Electrical) around two years.

Since last two years he is a student of the postgraduate program at Construction and Management, Department of Civil Engineering, Maharashtra Institute of Technology, Pune, India.

Her research interests are in construction materials, energy efficient buildings, architectural designs, Green building, building information modeling (BIM) and project management. She is a member of Iran Engineers Union. Presently, working on ME dissertation.

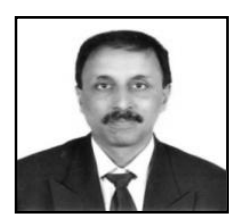

Dr. S. S. Pimplikar is presently Professor and Head of the Department of Civil Engineering, Maharashtra Institute of Technology, Pune, India

His subject Areas in Which he is teaching, are: Project Management, New Construction Materials, Accident Studies, statistical Methods, Estimation and Tendering and Financial Management.

His research interests are in construction materials, transportation engineering, green building, and project management. Presented papers in international conferences and published technical papers. He is a member of the Indian Road Congress, Indian society of Hydraulics and Indian Society of Technical Education. 